\title{
BMJ Open Learning needs, preferred learning methods and learning challenges of first five general practitioners in NHS Scotland: a qualitative study
}

\author{
David E Cunningham (1) , Caroline Ward, John Kyle, Lynsey Yeoman
}

To cite: Cunningham DE, Ward C, Kyle J, et al. Learning needs, preferred learning methods and learning challenges of first five general practitioners in NHS Scotland: a qualitative study. BMJ Open 2021;11:e044859. doi:10.1136/ bmjopen-2020-044859

- Prepublication history for this paper is available online. To view these files, please visit the journal online (http://dx.doi. org/10.1136/bmjopen-2020044859).

Received 22 September 2020 Revised 16 March 2021 Accepted 15 April 2021

\section{Check for updates}

(c) Author(s) (or their employer(s)) 2021. Re-use permitted under CC BY-NC. No commercial re-use. See rights and permissions. Published by BMJ.

Medicine Directorate, NHS Education for Scotland, Glasgow, UK

Correspondence to Dr David E Cunningham; david.cunningham@nhs.scot

\section{ABSTRACT}

Objectives To identify the learning needs and preferred learning methods of First5 general practitioners (GPs) in National Health Service (NHS) Scotland.

Design Qualitative research study using grounded theory methods. First5 GPs were interviewed in small focus groups or individual interviews in-person, or over the telephone depending on their preference.

Setting General practice in NHS Scotland.

Participants GPS, within the first 5 years of completion of GP training, who were working in NHS Scotland.

Results Thirty-eight First5s were recruited to the study. Participants recognised that gaps in their GP training became apparent in independent practice. Some of this related to NHS appraisal and revalidation, and with the business of general practice. They were interested in learning from an older generation of GPs but perceived that preferred learning methods differed. First5 GPs were less reliant on reading journals to change their practice, preferring to find learning resources that allowed them to gain new knowledge quickly and easily. There were considerations about resilience and of the challenges of learning in remote and rural areas of NHS Scotland. This related to travel costs and time, and to accessibility of learning courses. Participants appreciated collective learning and commented about the logistics and costs of learning.

Conclusions Preferred learning methods and learning resources differ with First5 GPs compared with those who have been in practice for some years. Learning providers need to recognise this and take these differences into account when planning and preparing learning in the future.

\section{INTRODUCTION}

Mirroring the approach of other UK countries, the Scottish Government's healthcare strategy has encouraged healthcare to be delivered at home by primary healthcare teams, reducing hospital admissions whenever possible. ${ }^{1}$ This strategy is reliant on a stable and secure primary healthcare workforce. The UK has experienced considerable difficulties over many years with the recruitment and retention of general practitioners (GPs)

\section{Strengths and limitations of this study}

- Study participants were diverse-drawn from 10 boards in National Health Service (NHS) Scotland and worked in urban areas, areas of deprivation and remote and rural areas.

- Roles held by participants were varied and included partners, self-employed locums and salaried general practitioners (GPs) with some having leadership roles in national organisations.

- No First5 GP from the three island NHS boards in Scotland were recruited to the study.

- NHS Education for Scotland provides education to First5 GPs and this may have biased the findings.

for its National Health Service (NHS). ${ }^{2-4}$ The NHS needs half of new medical graduates to enter a career in general practice but it is known that fewer than $20 \%$ made this choice in recent years. ${ }^{3}$

There are problems at both ends of the GP career path: older GPs are retiring early or reducing their clinical commitments; newly qualified GPs are choosing locum work or portfolio careers in preference to permanent GP partnership. Working less than full time is common. ${ }^{25}$ Various reasons have been given for this: low morale, increased workload and work intensity, and pension changes. ${ }^{6}$ The UK has attempted to recruit GPs from abroad to address the deficit but large international campaigns attracted fewer than forty GPs rather than the target of $500 .{ }^{7}$ A number of organisations predict that, by the middle of the 2020s, the NHS will be short of thousands of GPs. ${ }^{8}$

GPs within the first 5 years of completion of training have been called First $5 \mathrm{~s}$ by the Royal College of General Practitioners, which has called for additional resources to support them so that they will be retained and flourish as practitioners. ${ }^{9}$ Some of this support relates 
to education and learning in the initial years of clinical practice. $^{1011}$

Shiner and Howe found that newly qualified GPs wanted to be independent practitioners, but recognised they still gained from contact with their peer group, and valued discussions with more experienced GPs. ${ }^{12}$ They found that newly qualified GPs working as locum practitioners were isolated from the rest of the practice and from their peers. Torry ${ }^{13}$ called for action that encouraged a sense of community of practice for newly qualified GPs, and which promoted support and discussion among them to reduce isolation. Other research has focused on extending GP training and providing more educational resources during the transition to independent practice. ${ }^{14}$

It is important to plan educational endeavours and support systems with the involvement of First5 GPs and to identify their learning needs and learning method preferences. Thus, this study had the following research question: What are the learning needs and preferred learning methods of First5 GPs in NHS Scotland?

\section{METHOD}

A qualitative research approach using grounded theory methods was used to explore the perceptions and experiences of First5s in relation to their learning needs and preferred learning methods. A qualitative approach was considered appropriate as it would allow the research team to question participants and identify their reasons for their perceptions and experiences. This would not be possible using data collection instruments such as questionnaires. The study design consisted of a recruitment stage, data collection and data analysis, undertaken by four researchers. The first author is an experienced qualitative researcher and GP. The second author is a GP medical education fellow in NHS Education for Scotland (NES) and a First5 GP. The third and fourth authors are First5 GPs with some experience of qualitative research work.

\section{Recruitment}

First5s who were working in NHS Scotland and had completed GP training within sixty months of the beginning of the research period were included in the study. A purposive sampling strategy was adopted to maximise diversity of perceptions and experiences. A sampling grid was constructed that included remote and rural ( R \& R) GPs, those working in areas of deprivation, and the 14 territorial boards in NHS Scotland. First5s were contacted by email by one researcher and invited to take part in a focus group or one-to-one interview determined by their preference. Participants were sent a study information sheet giving details of its aims. They signed a consent form giving permission for their discussion to be audiorecorded and transcribed. An assurance was given that discussions would be confidential and transcriptions anonymised. A professional fee of $£ 75$ was offered to compensate for loss of earnings in recognition that some participants were working as self-employed locums, or working in Out-Of-Hours Services. Interviews and focus groups were held in mutually agreeable settings or using technology.

\section{Data collection}

A topic guide was devised by the researchers to help with the semistructured interviews. This was constructed by the researchers after exploration of the relevant literature and following team discussions concerning proposed questions. Interviews were held several weeks apart allowing researchers time to listen to audio-recordings, examine transcriptions and make adaptations to questions posed to subsequent participants, thus adopting an iterative approach. Transcriptions were made by NES clerical staff. Recruitment ended when data saturation was achieved. This was judged by the research team when no new perceptions and experiences were found from participants as the interviews and analysis progressed. It was confirmed by undertaking two further interviews to be sure of this.

\section{Data analysis}

Transcriptions were checked against the audiorecordings and corrections made by researchers. Transcriptions were read and reread independently by researchers who undertook initial analysis of the interviews they had done. All transcripts were read by DC. Data analysis followed the method described by Charmaz: codes were constructed and brought together into themes using the constant comparative method. ${ }^{15}$ Coding was undertaken separately by the researchers who met at regular intervals to discuss and agree emergent themes. Any themes causing disagreement were discussed and talked through until the research team reached agreement. Analytical memos were written and shared by the researchers. Mind maps were created for each transcript which helped researchers see connections between codes and themes and deepened analysis. ${ }^{16}$

\section{RESULTS}

Thirty-eight First5s were recruited to the study. Eleven were interviewed individually using three methods: in person, by telephone, or using videoconferencing technology. Four were interviewed in two paired interviews, and 23 were interviewed in seven focus groups ranging in size from three to five participants. Twenty-eight were female and ten were male. Participants were drawn from 10 of the 14 boards in NHS Scotland and table 1 gives details of participants and their NHS board location. Thirteen were from $\mathrm{R} \& \mathrm{R}$ areas and five worked in areas of deprivation. Seventeen participants described themselves as being salaried, six were locums and 15 were partners, with one partner working additionally as a salaried GP in another practice. Interviews started in November 2018 and ended in February 2019. All interviews (apart from two focus groups) were conducted by CW, LY and 


\begin{tabular}{lc}
\hline Table 1 & Participants and NHS board location \\
\hline NHS board & No of participants \\
\hline NHS Ayrshire and Arran & 5 \\
NHS Dumfries and Galloway & 1 \\
NHS Fife & 1 \\
NHS Forth Valley & 6 \\
NHS Grampian & 6 \\
NHS Greater Glasgow and Clyde & 11 \\
NHS Highland & 3 \\
NHS Lanarkshire & 1 \\
NHS Lothian & 3 \\
NHS Tayside &
\end{tabular}

NHS, National Health Service.

JK who were First5 GPs at the time of the data collection. One focus group was conducted by DC and another by a GP fellow within NES.

There were no participants from NHS Borders, NHS Orkney, NHS Shetland or NHS Western Isles.

Seven themes were constructed from the data and are shown in box 1.

\section{Perceptions of gaps in GP training}

Participants perceived the focus of training was to cover the curriculum and pass the Member of the Royal College of General Practitioners (MRCGP) examination. Some considered this encouraged broad learning, others perceived it was detrimental to their current learning needs, which were more focused and primarily determined by the needs of their patients and practice.

Because when you're an [GP]ST, you're studying in a way to pass exams. Your learning is more focused on that. Whereas now, it's actually on what you need to do day-to-day, and what's most useful to you and your patients. (Participant 31)

Several referred to the short duration of training and the difficulties of learning everything that GPs may encounter. Some recommended that training should be extended with more time spent in general practice.

\section{Box 1 Main themes}

Perceptions of gaps in general practitioner training.

Transition to independent practice.

Intergenerational learning.

Resilience.

Remote and rural issues.

Collective learning.

Logistics of learning.
I feel, probably, that the bare minimum of GP training is done, in terms of actually time in a GP practice and learning what a GP does. (Participant 27)

Others suggested that increasing the number, quality and relevance of secondary care posts would be beneficial. Most participants perceived that training was focused on clinical learning, leaving knowledge and skills of business, leadership and practice management as important learning needs for the first 5 years.

We don't really get taught the business side of general practice, and we don't really get taught leadership skills and I think that's so important if you are becoming a partner. I think there's not anything about the business of general practice in training and I think that's wrong and I think if I was changing one thing it would be encompassing a bit of leadership skills. (Participant 5)

Some considered these topics should be taught more thoroughly during training but others suggested they were more relevant after training:

As an ST3 I had like a tutorial just with the practice manager who went over the running [of the practice] and finance side of things, but it was pretty much all over my head! (Participant 12)

Participants held contrasting views on how these topics were best learnt: some viewed a formal course as effective and others suggested that they were best learnt by becoming involved.

I think having a one or two day course or a week long course even to see what is expected would be really helpful. (Participant 7)

I think what I've learned about sort of the businessy side of things, I have learned from how we run and how we work and I think the problem with something that's more generic than that is that every practice is going to run slightly differently. (Participant 30)

Appraisal and revalidation were important learning topics not covered during training and were common learning needs for newly qualified First5s.

I don't really understand appraisal yet, I don't really know what I'm supposed to do for it. (Participant 18)

Experienced First5s were more familiar with appraisal and revalidation, but considered the processes often detracted from useful learning, with the challenges of documenting evidence of learning activity for appraisal.

I'm using NICE CKS [National Institute of Clinical Excellence-Clinical Knowledge Summaries] every day but I'm not able to log that because it's so much just part of my working day. I'm not going to log every 20 minutes or half-hour that I spend looking at something. And maybe I should be, but there isn't an easy 
way for me to do it at the moment, so I can't log that stuff. (Participant 21)

\section{Transition to independent practice}

The transition from supervised trainee to independent practitioner was a time of challenge. Loss of dedicated supervision from their trainer and wider training practice, isolation from training peers, and adapting to work in a new practice or unfamiliar working environment, were common concerns. Participants recognised their limited opportunities to ask colleagues for advice compared with training.

As a qualified GP, if I'm unsure about something, I probably am more likely to phone secondary care for a discussion with a specialist rather than, as a trainee, I might have spoken to my trainer because you have those sessions. (Participant 15)

You may even be single-handed in a practice which is such a steep learning curve coming out of ST3. You might be the only person in a practice, doing home visits completely on your own and not really having anyone to talk to, it's like: 'Argh!' (Participant 16)

Participants identified learning needs arising from reflections about patient encounters and perceived gaps in knowledge. Some had a personal interest in a topic and a desire to remain up to date. Fear, clinical uncertainty and lack of confidence were motivators for learning.

I try and choose things that I... that is likely to walk into my consulting room in the next week. Things that are common and relevant to my own practice, even if it's something that I'm not that interested in, but it's something I maybe should know. (Participant 26)

Participants used a variety of learning resources with many keen to learn from the knowledge and experience of colleagues, secondary care specialists, and from reading accessible reference guidelines and online resources. Most felt it was important to attend courses which were valued when they consisted of a variety of short clinical updates reflective of the breadth of general practice work. Learning should be easy, convenient and quickly obtained, and relevant to clinical work.

I just come across stuff and realise I don't know it, or I need to know more about it, and then find out the answers. I've never found a more structured way that I can find what I need. I guess I like to have that immediacy to it. (Participant 23)

\section{Intergenerational learning}

Intergenerational learning was beneficial for some participants. Contrasting learning approaches were attributed to different ages of practitioners and seen as a barrier to effective interactions between First5s and older GPs. Older GPs were considered less likely to learn using technology and more reliant on printed resources like books and journals. First5s read journals infrequently which accumulated at home unopened in their wrappers.

My training practice had a few older GPs and their rooms were full of books and the reason for that is the internet didn't exist [when they were a GP trainee] so they had to go to a book to read it. (Participant 5)

Got a healthy stack of BMJs [British Medical Journal] still in their packets. (Participant 18)

Older GPs were considered confident to learn through experience. First5s valued experiential learning but expressed reservations and preferred more formal learning.

I think they [experienced GPs] are more likely just to do things, to learn by doing it, whereas we'd be wanting to learn more about it first. They are more likely just to have a go at something. (Participant 7)

Participants suggested that changes in training influenced differences in learning styles between older and younger GPs. They preferred to learn with people who shared their approach to continuing professional development (CPD), influenced by recent training and the eportfolio system.

It's a bit difficult because there's been a bit of a sea change in GP education. I think, certainly the ten year age gap makes a bit of a difference in terms of how people approach things. So yeah, it might be nice if there were more younger people. (Participant 24)

First5s preferred to learn with their peers, particularly in settings such as Practice-Based Small Group Learning (PBSGL), where professional socialisation and group learning were valued. More experienced First5s valued CPD with senior colleagues as they gained confidence.

When you are first qualified, the first couple of years it can be quite intimidating going to stuff with a lot of older GPs. Like: 'Oh, gosh! I am just the newbie here!' Then, I think now it wouldn't really bother me and you would probably learn lots from them. (Participant 12)

\section{Resilience}

Resilience was considered by many participants, who discussed factors reducing their ability to remain resilient, including heavy workloads and professional isolation. These influenced the content, format and timing of CPD undertaken by participants. Several discussed their lack of experience of clinical presentations despite having finished training and judged clinically competent. Maintaining a work-life balance, and incorporating CPD into this was important to participants, particularly those with families. Most considered that CPD required protected 
learning time (PLT) within the working day, separate from clinical duties and home life.

I think sometimes if there's a dedicated time and place to be that you have cleared your decks and that's where you are for that time and therefore you know you're not necessarily gonna get disturbed by other things. (Participant 19)

Learning to be resilient and avoiding burnout were considered difficult, as learning needs varied from person to person. Common themes included practising realistic medicine, the management of challenging patients with complex social and mental health problems, and managing time and patient demand.

How to say no to patients, how to... We're taught as GP trainees to be so lovely and understanding and listen to every single problem but in real life that is gonna burn you out so a way to sort of be nice but be firm. (Participant 3)

We can end up taking on lots and lots and lots, and that's often the kind of mentality of people who go into medicine and general practice anyway. So, something to kind of push people away from that. They're like: 'We don't actually have to do that. Just do your job and think about who can do that bit of your job'. To me, that's what resilience is. To me, that's really helpful to be reminded of that every so often... I think there is a skill to that as well, isn't there? You can say yes to everything and burn out by the time you're 40 , or you can start to teach people about where the boundaries are for you in a nice way that doesn't ruin your relationship with them.(Participant 21)

Self-care, emotional intelligence and maintaining good mental health were important. Participants were conscious they were beginning a long career and would be practising for decades.

I went to a talk that actually a CBT [cognitive behavioural therapy] therapist was at and she was explaining what advice she gives to patients, you know, when they go with anxiety and all this and it was really relevant actually to GPs managing life in general, like their own life and their own work load. (Participant 3)

\section{$R$ \& $R$ issues}

Some concerns were specific to $\mathrm{R} \& \mathrm{R}$ practitioners. CPD access was a particular concern, and R \& R First5s identified inequity in CPD provision, feeling disadvantaged and unsupported by national GP organisations. At one focus group, a new First5s who had trained in a rural setting considered that participants from island NHS boards were missing as they were unable to travel to the mainland.

There's definitely no faces here today that I recognise from the trainees that were on any of the islands...I guess they're just not... [present] (Participant 17)
Access issues centred around cost, including travel and accommodation, and time away from practice and family.

The ** courses [commercial CPD organisation] are $£ 100$ to $£ 200$ and they start at what, 8:30, 9:00 in the morning? So, you're going to have to stay the night before. And then you do the whole course the whole day, they're quite tiring, so you might want to stay the night after as well. So, you've got to have dinner and you have to pay for parking and the costs really do add up. (Participant 21)

Professional socialisation of attending courses was viewed positively by $\mathrm{R} \& \mathrm{R}$ participants, with the exchange of ideas valued by those who were relatively isolated.

You get the option to meet people outside who you normally work with. You can actually find out what other practices are doing, or what the rest of the world is doing, because it can get quite small otherwise, if you're just in your wee town on the **** coast miles away from everywhere else. (Participant 25)

Funding of travel expenses for R \& R GPs was discussed as a way to encourage course attendance. There was a suggestion that isolated GPs would benefit most from learning with others, and that dedicated funding could support this.

There's not really much allowance in GPs contracts for fixing a kind of funding formula where it encourages or at least creates a level playing field for rural GPs to access things even though they are the people that benefit from it the most. So yeah, if I was doing something, I would create some sort of rural general practice learning fund. You could identify two days of learning a year with your appraiser, and then, rather than NES paying for the course, they could fund the practice's locum fees for you to go on the course for two days or something like that. (Participant 23)

Some R \& R participants considered their learning needs were different compared with urban colleagues with more focus on acute presentations of serious illness and injury.

I think you just need to learn to manage things quite differently. The acute obstetrics, query ectopics, [possible ectopic pregnancy emergency] things like that, sick children, all of that has to go down the road which is two hours/two and a half hours on a good day. You need to make the decision of: 'Do they need to go today or not?' Because equally it's a terrible road, terrible weather conditions, you won't always get an ambulance. (Participant 19)

Acute care and prehospital care courses were essential for R \& R participants. Those who completed them had to self-fund, leading to resentment about covering gaps in GP training. 
I think the funding side of it grates a little bit. I did choose to work rurally I suppose and in many ways these courses aren't specified as being necessary. However, working here I think they are necessary and I think particularly close to CCT in those First5 years I think some of these things are not really covered within, you know, they're not really covered as well perhaps during the curriculum. (Participant 19)

This suggested that $\mathrm{R} \& \mathrm{R}$ practice was more challenging for First5s due to their inexperience. First5s sought out learning to counter this and reduce concerns about clinical uncertainty. Concerns were raised about providing services to Police Scotland particularly assessing patients in police custody with no prior training or supervision in this work.

I just think it's a national scandal really. There's so little regulation and there's so little training. I really don't think we should be able to be a police surgeon without having done at least a weekend competency course or something like that. (Participant 23)

Some reconsidered their future in rural practice because of a lack of police work training.

I've really had to reflect on whether or not I want to continue working in this area because of the police surgeon role. And I've argued for...if there's not any national level training then at least it needs to be ***** [name of locality] wide training at out of hours meetings and things. They're very good at seeming to take you on board and writing down in the minutes, say: 'We'll get back to you.' And then nothing's happened after a year. I've got no hope of them doing anything locally. (Participant 23)

Participants appreciated webinars: they were low cost learning methods which could be attended in the evening and from home. Their short, interactive nature was in keeping with participants' preferred learning methods.

\section{Collective learning}

Different formats and benefits of collective learning were identified. Interactive case-based learning was attractive and helped engagement in the topic. It increased understanding by learning how others pragmatically applied guidelines to real-life scenarios.

Everyone loves listening to a story, when someone has been there and you can identify with them and think: 'Oh! This is what they did, this is how it went wrong and this is how they dealt with it.' You think: 'Well, I don't have to make their mistakes.' (Participant 4)

It needs to be reasonably varied, it needs to be casedbased for me, rather than just having a list of slides and going through things. That is quite interactive. Even if you have a small session or you have a discussion, you can go over things. (Participant 33)
Most had experience of PBSGL which was available in Scotland and participants were encouraged to use during training. Many continued in their group after training, benefitting from peer support, professional socialisation, and a safe environment to discuss and reflect on practice.

I find PBSGL specifically really useful from a kind of reflective point of view, so speaking to other GPs in my group about cases that are relevant to the topic and kind of just exploring the difficulties that we've had within our own practice and almost like [a] kind of Balint group talking about communication that way. I think that's quite supportive, particularly given that I'm locuming at the moment so I don't necessarily have that relationship with the kind of senior GPs in the practice, although I do to some extent but I'm just not there all the time. So it is nice to have it out with the practice as well. (Participant 1)

The value of PBSGL was dependent on the group's dynamics. Some struggled to keep their group going after training and others considered they would benefit from having experienced colleagues join their group. A few had difficulty joining established local groups.

I think it would be quite a reason not to join one'cause you might be a bit socially intimidated from it, from meeting all these people, you know, it's a big jump isn't it? It's like going to a gym class the first time, putting yourself out there.(Participant 3)

Interprofessional learning either within a practice or with primary or secondary care colleagues increased participants' understanding of others' perspectives and roles in patient care. Regular discussions strengthened relationships and improved confidence with colleagues.

I think it's [PBSGL] good especially with pharmacists and nurses because they look at it in a different way. They quite often know different things about conditions and management and can help you understand things better. (Participant 34)

Learning with the wider primary care team may be less useful as learning needs differed with individual's roles. Learning from secondary care needed to have a primary care perspective to ensure relevance for GPs.

There is a big difference between the ones who - consultants - who just tell you about the topic, and the ones who tell you about [it] from a GP point of view, and it definitely has to be from a GP point of view now. If they come in and tell us about all these fancy, exciting new things that are hospital-only then we don't get much out of it. But if it's really like: 'As a GP this is what you should do when you see someone with this.' You know that would be great. (Participant 6)

Social media such as Facebook and Twitter were sources of easily accessible learning. Viewing the posts of others or posing questions, either within private 
GP groups or from own their own accounts to their followers, were valued. Some were concerned about information being correct and confidential and that posts could be taken out of context or shared beyond a private group.

I have used Twitter a little bit for just asking clinical questions: 'Has anyone done this?' That kind of thing and I collected Twitter people that must use it. Yes, so it's quite good. (Participant 36)

I think I find those make me feel anxious because it is unfiltered, and you don't actually know who you are actually speaking to or how highly qualified they are. (Participant 37)

\section{Logistics of learning}

Cost was the most cited barrier to attending learning events. Most found that costs were high with some arguing that specific funding should be available. This related to event fees and travel, subsistence, accommodation and additional childcare costs. Locum GPs cited potential loss of earnings when attending weekday courses.

The cost of that and having to take a day off work or use annual leave as well as paying a significant amount of money to go, it's sometimes just: 'Ah, I won't bother, I'll do something else.' (Participant 3)

Timing and accessibility were major issues with participants divided on the optimum timing for learning events. Some viewed weekends or evening meetings as the most convenient as it did not involve taking time out of practice.

I know if I can come on a weekend and I don't need to worry about getting time off or getting a locum or taking study leave. (Participant 3)

I don't mind doing the odd evening if it is a topic that, I really have, I have a particular interest in. Every once in a while I will do an evening because I would prefer to give up an evening than a weekend but that's just personal preference. (Participant 13)

In contrast, participants with young families or those based outside cities, preferred to learn during the working day, keeping their evenings free for family life, or limiting driving to urban locations for an evening meeting.

I don't really like going from work and not seeing the kids, maybe not getting home until quite late. So, timing is a big thing. (Participant 11)

I worked rurally for two years and it was difficult because a lot of the update things would all be in the city and then you maybe have got an hour and a bit drive to get to that in the evenings. And certainly that could quite limit your access unless you are taking whole days off. (Participant 38)

There were several reasons for the different timing preferences for learning events. Partners and salaried GPs cited high workload and difficulty obtaining study leave or locum cover to attend during the working week.
It's far more difficult to take time away from your normal working day as a partner than it has been ever before. (Participant 27)

Locum GPs had fewer opportunities to learn from practice and from colleagues and had to spend time learning outside working hours to compensate.

I think that's where it's a little bit more difficult being a locum, because I will go back to the practice and actually see myself, going back to patients I've seen before to try and work out what's happened. Whereas someone that may be salaried, would be seeing these people back and reflecting on what you've done last and what you should do next, so it's definitely more difficult in that respect being a locum. (Participant 16)

\section{DISCUSSION}

\section{Main findings}

The aims of this study were achieved. Participants recognised that there were gaps in their GP training that became apparent in independent practice. They were interested in learning from an older generation of GPs but perceived that preferred learning methods differed between them. There were considerations about resilience and of the CPD challenges in R \& R areas of NHS Scotland. Participants appreciated collective learning and commented about the logistics and costs of learning. The study had aimed to identify the learning needs and preferred learning methods of the first 5 GPs but in addition, we identified the challenges faced by these GPs in their learning activities.

\section{Strengths and limitations}

The study had a number of strengths. Participants were diverse and held contrasting opinions producing rich data. They worked in urban and R \& R areas, as well as in areas of deprivation, and were drawn from 10 of the 14 boards in NHS Scotland. They were recruited from a range of experience in the first 5 years since GP qualification: some recently finishing training whereas others had worked as GPs for just under 5 years. Participants held diverse roles including partners, salaried GPs, locums and some had portfolio careers. Some held leadership and representative roles in national general practice and medical organisations.

Data saturation was achieved and confirmed by the last two interviews. The data were collected and analysed by researchers who were primarily First5s and thus close to the data and subject area. Each transcript was analysed by two researchers adding a sense of confirmation to the findings. Discussions at research meetings and the writing and sharing of memos deepened analysis.

There were limitations to the research. No participant took part from the three island boards in NHS Scotland and they may have held different views from mainland GPs. Researchers were based in NES which provides GP education and this may have biased the recruitment of participants and data analysis. Furthermore, as three 
of the four researchers were First5 GPs and acquainted with some of the potential participants, this may have influenced who responded to the invitation to participate, and what was said at interview. Details of individual participant's length of experience and of any leadership and representative roles are not included to protect the anonymity of participants.

\section{Comparison with existing literature}

Taylor et al surveyed the learning methods of First5 GPs in 2010 and found that $56 \%$ of respondents read medical journals often or very often. ${ }^{11}$ Our qualitative results, although not directly comparable with survey methodology, suggested that learning by reading journals had fallen out of favour with our participants. Taylor's survey agreed that First5s cited the business of general practice as being a common learning need-this too was identified by participants in our study as being an important learning need.

Dowling et al have undertaken research in Ireland which has a broadly similar population and demography to that of Scotland. Their research has shown that CPD involving small group learning is well-received in Ireland and it is considered a supportive learning resource by GPs in R \& R practice. ${ }^{17}$ This was comparable to our findings related to acceptability and appreciation of the Scottish PBSGL programme which involves small group learning. Dowling et al assessment of learning needs of GPs in Ireland found similar needs between urban and R \& R GPs, apart from prehospital care of emergencies which was a need identified by R \& R GPs. ${ }^{18}$ These learning needs were identified by our study with the addition of learning needs related to police surgeon work which may be peculiar to $\mathrm{R} \& \mathrm{R}$ areas in Scotland in contrast to other countries of the UK.

The Shape of Training Review led by Greenway in 2013 suggested that time spent in GP training may need to be longer. ${ }^{19}$ This would benefit First5 GPs, particularly those who continue their careers in $\mathrm{R} \& \mathrm{R}$ areas, where the need for broad medical care may require a longer time in training.

\section{Implications for further research and change in practice}

The Scottish Government is investing in general practice and primary care, and the launch of a new contract for GPs is one of the actions. ${ }^{20}$ First5s need additional investment in the provision and support for CPD particularly in $\mathrm{R} \& \mathrm{R}$ areas. This could include the development of small group learning and other resources that encourage discussion and professional socialisation-key needs for First5s. PLT is an important issue for First5s who are keen to separate learning from work and family life. NHS boards need to invest more in this area. First5s were keen to learn using technology such as webinars and podcasts and GP CPD providers may need to offer more of these to engage with younger GPs. This may be appropriate and safer in a post-pandemic world. Those who are charged with providing CPD may come from a different generation from First5 GPs and need to take into account that learning experiences and preferences may be different.

\section{Declaration of interest}

DC is an assistant director within NES and provides CPD resources (including PBSGL) to GPs and their teams in Scotland. CW was a medical education fellow within NES. All authors are practising GPs in the West of Scotland.

Acknowledgements The authors would like to thank all participants and administrative staff in NES who helped in this study. The authors thank Dr Neave Corcoran for her help in moderating one of the focus groups. The authors thank the Scottish Government for its support of the First Fives educational and research service within NES.

Contributors DC conceived the study, recruited the research team and searched the existing literature. DC, CW, JK and LY collected the data and analysed it. DC, $\mathrm{CW}$, JK and $\mathrm{LY}$ contributed towards the results and discussion sections of the manuscript. DC wrote the introduction and methods sections. DC, CW, JK and LY edited the manuscript.

Funding The authors have not declared a specific grant for this research from any funding agency in the public, commercial or not-for-profit sectors.

Competing interests DC works for NHS Education for Scotland (NES) and LY and CW were medical education fellows for NES.

Patient and public involvement Patients and/or the public were not involved in the design, or conduct, or reporting, or dissemination plans of this research.

Patient consent for publication Not required.

Ethics approval Under UK 'Governance Arrangements for Research Ethics Committees', ethical research committee review is not required for service evaluation or research which, for example, seeks to elicit the views, experiences and knowledge of healthcare professionals on a given subject area. Similarly 'service evaluation' that involves NHS staff recruited as research participants by virtue of their professional roles does not require ethical review from an established NHS research ethics committee.

Provenance and peer review Not commissioned; externally peer reviewed.

Data availability statement Data are available on reasonable request. Data include transcripts of audiorecordings of interviews and regarded as being confidential. Participants did not consent to this data being shared.

Open access This is an open access article distributed in accordance with the Creative Commons Attribution Non Commercial (CC BY-NC 4.0) license, which permits others to distribute, remix, adapt, build upon this work non-commercially, and license their derivative works on different terms, provided the original work is properly cited, appropriate credit is given, any changes made indicated, and the use is non-commercial. See: http://creativecommons.org/licenses/by-nc/4.0/.

ORCID iD

David E Cunningham http://orcid.org/0000-0002-0415-9807

\section{REFERENCES}

1 The Scottish Government 2020 vision for health and social care. Available: https://www2.gov.scot/Resource/0042/00423188.pdf

2 Owen K, Hopkins T, Shortland T, et al. GP retention in the UK: a worsening crisis. findings from a cross-sectional survey. BMJ Open 2019;9:e26048.

3 Marchand C, Peckham S. Addressing the crisis of GP recruitment and retention: a systematic review. Br J Gen Pract 2017;67:e227-37.

4 Rosenthal J, Chana N. Future-proofing primary health care: GP recruitment and retention in the new NHS. Br J Gen Pract 2011;61:430-1.

5 Lambert T, Goldacre M. Trends in doctors' early career choices for general practice in the UK: longitudinal questionnaire surveys. $\mathrm{Br} J$ Gen Pract 2011.

6 Smith F, Lachish S, Goldacre MJ, et al. Factors influencing the decisions of senior UK doctors to retire or remain in medicine: national surveys of the UK-trained medical graduates of 1974 and 1977. BMJ Open 2017;7:e017650.

7 Rimmer A. International recruitment scheme brings 38 GPs to NHS. BMJ 2017;358:j3462. 
8 The Nuffield Trust predicted shortages of GPs. Available: https:// www.nuffieldtrust.org.uk/files/2019-10/general-practice-without-gpsv2.pdf

9 First Fives Royal College of General Practitioners. Available: https:// www.rcgp.org.uk/first5 [Accessed 8 Feb 2021]

10 Taylor CJ, Parsons J, Sparrow N, et al. First5®--a UK initiative relevant to the global general practice community. Eur $J$ Gen Pract 2012;18:229-32.

11 Taylor C, Turnbull C, Sparrow N. Establishing the continuing professional development needs of general practitioners in their first five years after training. Educ Prim Care 2010;21:316-9.

12 Shiner A, Howe A. Professional learning during the transition from trainee to newly qualified general practitioner. Educ Prim Care 2013;24:346-54.

13 Torry R. The importance of peer support for new GPs during their transition to independent practice. Educ Prim Care 2011;22:144-7.

14 Tulinius C, Hølge-Hazelton B. Continuing professional development for general practitioners: supporting the development of professionalism. Med Educ 2010;44:412-20.
15 Charmaz K. Constructing Grounded Theory. 2nd edn. Thousand Oaks, CA: Sage, 2013

16 Mind maps. Available: https://www.mindgenius.com/[Accessed 8 Feb 2021].

17 Dowling S, Last J, Finnegan $\mathrm{H}$, et al. Does locally delivered small group continuing medical education (CME) meet the learning needs of rural general practitioners? Educ Prim Care 2019;30:145-51.

18 Dowling S, Last J, Finnegan $\mathrm{H}$, et al. What are the current 'top five' perceived educational needs of Irish general practitioners? Ir J Med Sci 2020;189:381-8.

19 General Medical Council. The shape of training final report. London: The General Medical Council, 2013. https://www.gmc-uk.org/-/ media/documents/shape-of-training-final-report_pdf-53977887.pdf

20 The Scottish Government. The Scottish Government new GMS contract. Edinburgh, UK: The Scottish Government, 2018. https:// www.gov.scot/publications/gms-contract-scotland/ 